\title{
Fast-Track in-Stream Action to Enhance the Oxidative Capacity within Watershed
}

\author{
Mohamed L. ElKhazragy, Minerva E. Matta, Khaled Z. Abdallah
}

\begin{abstract}
This work presents a non-conventional alternative for cleaning polluted agriculture drainage network within a certain watershed. In Egypt, a need for using marginal quality water in agriculture applications is becoming a great necessity due to water shortage. One important strategy to increase available water resources is to reuse agriculture drainage water for irrigation application. The water system, especially drainage network receives a remarkable amount of pollution (raw and partially treated wastewater). That results to an increase in organic load to an unacceptable level, accordingly, the water quality of the drainage water has been negatively affected and the "reuse" plan has been threatened. Fast-Track In-stream Action (FTIA) is an ongoing fast action suggested to control the pollution of drainage water within a certain watershed to make it more suitable for reuse practice. FTIA as a quick interfere will skip long-term processes of conventional water treatment stages to get satisfactory results in proper time. It presents a practical immediate solution to achieve acceptable level of water quality rather than waiting for full improvement through long-term and expensive conventional programs. In this study a biological maintenance solution was applied and tested in both bench and field scales to assess its efficiency in improving the water quality within selected watershed. An evaluation of this fast-track process was done by measuring a significant key water quality parameters (WQPs) at designed locations of the study area before, during and after application of material. For better explanation of overall water quality and proper comparison, a weighted arithmetic water quality index (AWQI) has been discussed based on eight selected WQPs. In addition to a bench-scale test, two other field investigations were adopted: the first one investigates the effects of fast-track resources when applying the bio-based material under high flow condition with intermediate shock flow (study area "1"), while the other one examine the application of material under low flow condition with intermediate shock pollution load (study area "2"). All indicators, including aesthetics showed improvements in selected WQPs and AWQI during the investigation period
\end{abstract}

Keywords: Bio-based material, Drainage water reuse (DWR), Fast-track action, GIS, Point source of pollution (PSP), Water quality management, Watershed, Water Quality Index (WQI).

\section{INTRODUCTION}

In Egypt, the Nile River supplies $73 \%$ of fresh water directly to different usages, while the reminder mostly comes

Revised Manuscript Received on February 05, 2020.

* Correspondence Author

Mohamed L. ElKhazragy*, Water Quality Management Unit, Water Research Center, Cairo, Egypt. Email: elkhazragy@gmail.com

Minerva E. Matta, Environmental and Sanitary Eng. Division, Faculty of Engineering, Cairo University, Cairo, Egypt. Email: minerva.edward@gmail.com

Khaled Z. Abdallah, Environmental and Sanitary Eng. Division, Faculty of Engineering, Cairo University, Cairo, Egypt. Email: civil3e@civil3e.com

(c) The Authors. Published by Blue Eyes Intelligence Engineering and Sciences Publication (BEIESP). This is an open access article under the CC BY-NC-ND license (http://creativecommons.org/licenses/by-nc-nd/4.0/) indirectly from the reuse of drainage water [1]. The rapid deterioration in water quality is one of the most important factors that increase the stress on Egypt's water resources. Water of good quality is becoming increasingly scarce and therefore more costly, One strategy to increase available water resources is to reuse agriculture drainage water. The detrimental effects of drainage water reuse can be minimized by adopting appropriate pollution sources management.

In this study, a fast-track action strategy has been proposed: Fast-Track In-stream Action (FTIA) strategy can be achieved by introducing the following tools: 1 - fast-track scheme to easily describe the target watershed by using Geographical Information System (GIS) [2] and using 2- fast-track resources as a bio-based material to directly target the hot spots within the watershed. Fast-track action strategy as a quick interfere is a practical and unconventional solution to achieve an immediate partial improvement of present water quality and environmental status within a certain watershed. The watershed as a fast track-scheme is a premier water system unit for best management rather than administration boundaries scheme, where whatever is dumped in watershed's upstream ends up downstream. The primary field investigation showed that the main pollutant in the drains is organic contamination, which is impacting a number of key WQPs. The fast-track resource used in this study is a bio-based material that has several applications including agriculture, composting, and bioremediation. It provides a sustainable risk free alternative to any biological system and are manufactured as dry powder.

\section{Problem statement}

The low level of sanitation service especially in rural areas makes nearby streams (either canals or drains) the perfect places for inhabitants to dispose of their sewage [3]. With the continuous pollution dumping to the water system, the capabilities of a natural system to process the pollution is getting low. Most water policies adopted traditional strategies with continues dumping in water streams without serious consideration to its environmental effects on downstream, even when be considered, they were superficially touched within isolated administration boundaries.

Lack of investment and time required to complete establishment of planned conventional wastewater treatment plants (WWTPs), become a constrain impeding the improvement in surface water quality. Furthermore, the majority of existing WWTPs are aging and overloaded and facing the problem of lack of investment for operation and maintenance. The need to fast-track action strategy within watershed boundary rather than administration one, as an emergency management alternative is getting urgently needed nowadays. 


\section{MATERIAL AND METHODOLOGY}

FTIA carried out a validation program using bio-based material to enhance the oxidative capability of the selected streams within the study area. The fast-track resources used in this study is a bio-based non-hazardous, non-toxic material. It is a combined blend of microorganisms, enzymes, and co-factors. The material was produced from naturally, no genetically modified microorganisms (GMO). The bio-based material that has been selected for this study is called "BiOWiSH Aqua" by BiOWiSH Technologies International Inc. originated from United State. It was found to be effective in restoring water quality under appropriate conditions. It acted as a powerful biocatalyst to improve the biological transformation of polluted water. The fast-track resources bio-based material can be applied either along the stream (drains, canals) or at the point sources of pollution (e.g., low efficiency WWTPs, septic tanks and fish farming). The evaluation has been conducted by testing the material in two stages as illustrated in diagram figure 1: - bench scale test under manageable conditions; and - In-field test, with intermediate shock flow and load. In stage 1 a "fast-track analysis" has been carried out by measuring a significant key WQPs of a nearby heavily polluted drainage water under laboratory conditions (bench-scale test). In stage 2 a "fast-Track analysis" has been carried out at designed locations (surface water) of heavily polluted surface water (study area "1" and "2"), before, during, and after applying the bio-based material. A distance ranged from 250 to $800 \mathrm{~m}$ was chosen to test the capability of biocatalysts to break down the pollutants. The analysis was carried out and verified by three accredited official laboratories. The output results were used in comparing WQPs and calculating AWQI AWQI is regularly used as simple tools to provide a single number that expresses overall water quality at a certain location and time and summarizes WQPs into simple description (e.g., excellent, good, bad, etc.), for reporting to managers and the public in a consistent manner [4].

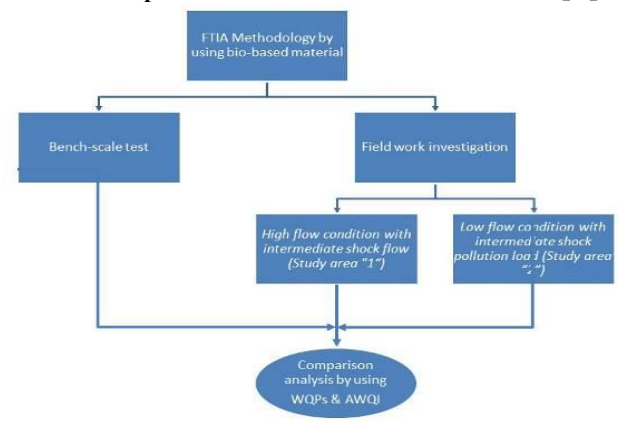

Figure 1: Methodology flow chart

\section{DISCUSSION}

\section{Water quality index calculation}

The calculation of the WQI was done using weighted arithmetic water quality index (AWQI) [5] as in the following form:

$$
A W Q I_{A}=\sum_{i=1}^{n} w_{i \mathrm{i}} Q_{i} / \sum_{i=1}^{n} w_{i \mathrm{i}}
$$

Where $n$ is the number of variables or parameters, $W_{i}$ is the relative weight of $i^{\text {th }}$ parameter and $q_{i}$ is the water quality rating of $i^{\text {th }}$ parameter. The unit weight $\left(W_{i}\right)$ of the various WQPs are inversely proportional to the recommended standards for the corresponding parameters. The value of $q_{i}$ is calculated using the following equation:

$$
q_{i}=100\left[\left(\mathrm{~V}_{\mathrm{i}}-\mathrm{V}_{\mathrm{id}}\right) /\left(\mathrm{S}_{\mathrm{i}}-\mathrm{V}_{\mathrm{id}}\right)\right]
$$

Where $\mathrm{V}_{\mathrm{i}}$ is the observed value of $i^{\text {th }}$ parameter, $\mathrm{S}_{\mathrm{i}}$ is the standard permissible value of $i^{\text {th }}$ parameter and $V_{\text {id }}$ is the ideal value of $i^{\text {th }}$ parameter. All the ideal values $\left(\mathrm{V}_{\text {id }}\right)$ are taken according to the acceptable level of chosen parameters. The calculation of AWQI was carried out in three main steps: 1parameter selection; 2- assignment of parameters weights and 3- aggregation of sub-indices to produce a final index score.

\section{Parameters selection, weighted and standards}

The basic function of any WQI is to consolidate several concentrations for different WQPs into a single numerical value. However, the importance of these parameters is mainly attributed to the possible water use [6]. The selection of WQPs and assigning their relative importance related to the drainage water reuse (DWR) in irrigation and fish farming were carried out by studying previous efforts in this field and that parameters which are affected by applying the bio-based compound and weighted accordingly (Table 1). For the selected WQPs, national standards (law 48 for the year 1982 and related amendment for the year 2013) were used as reference for setting parameters standard values. It is clear that the highest weights were given to the WQPs: BOD, COD, and TSS, where those parameters are essential in describing the biological pollution. In addition, oil \& grease levels in water are of prime concern in different applications.

Table 1 - Selected WQPs and their assigned weights

\begin{tabular}{|c|c|c|}
\hline $\begin{array}{l}\text { Parameter } \\
\text { (WQP) }\end{array}$ & $\begin{array}{c}\text { Water Quality } \\
\text { Standard }\end{array}$ & Weight \\
\hline BOD (mg/ L) & 10 & 0.23 \\
\hline COD (mg/ L) & 15 & 0.21 \\
\hline TSS (mg/L) & 50 & 0.25 \\
\hline $\begin{array}{l}\text { FC (MPN/ } \\
100 \mathrm{ml})\end{array}$ & 5000 & 0.01 \\
\hline $\mathrm{NH}_{3}(\mathrm{mg} / \mathrm{L})$ & 0.5 & 0.04 \\
\hline TP (mg/ L) & 3 & 0.01 \\
\hline $\begin{array}{l}\text { FS (MPN/ } \\
100 \mathrm{ml})\end{array}$ & 100 & 0.01 \\
\hline $\begin{array}{l}\text { DO } \mathrm{H}_{2} \mathrm{~S}(\mathrm{mg} / \\
\text { L) }\end{array}$ & 5 & 0.08 \\
\hline Oil \& grease & 1 & 0.17 \\
\hline $\begin{array}{l}\text { E. col (MPN/ } \\
100 \mathrm{ml})\end{array}$ & 5000 & \\
\hline$\sum$ & & 1 \\
\hline
\end{tabular}
and standards

Notes: BOD: biological oxygen demand; COD chemical oxygen demand; TSS: total suspended solid; FC: fecal coliform; TP: total phosphorus; FS: Fecal streptococci; DO: Dissolved oxygen; $\mathrm{H}_{2} \mathrm{~S}$ : Hydrogen sulphide. E. coli: Escherichia coli

\section{Bench-scale test}

The bench-scale test was conducted for fourteen days' period (the time life of the bacteria of bio-based material is nine days). The test aims to verify the oxidative capability of the bio-based material under controlled conditions within confined polluted water body. The dosing solution has been prepared according to company's recommendations, by adding 25 gm of compound into 25 liters of water and mixing properly (steering and aeration) for 4 hours (concentration of solution was $1 \mathrm{gm} / \mathrm{liter}$ ). 
A sample of 100 liters was collected from its original source (agriculture drain) and send to the laboratory for investigation in isolated iced tank. The 100 liters' ambient sample was divided into two. The first 50 liters was the control sample (CS), while the other 50 liters was the test one (TS). $250 \mathrm{ml}$ of dosing solution was added to the test tank with steering (concentration of ambient water $5 \mathrm{mg}$ / liter), and add maintenance dose to the test tank of $100 \mathrm{ml}$ on the fifth day. A set of 46 WQPs were tested to evaluate the capabilities of the material to clean ambient sample under controlled conditions (bench scale), while only eight WQPs: BOD; COD; TSS; $\mathrm{NH}_{3} ; \mathrm{FC} ; \mathrm{H}_{2} \mathrm{~S} ; \mathrm{FS}$ and E. coli were selected for AWQI calculation.

\section{Field work (surface drainage water)}

Prior to field investigation, a preliminary field test was conducted to detect the level of pollution in ambient water and to ensure the suitability of surface water to accommodate the bio-based material in terms of the salinity and toxicity. The pre-investigation process shoes that the Ammonia $\left(\mathrm{NH}_{3}\right)$ saturation parameter at the sampling location of study area "1" was $3.5 \mathrm{mg}$ / liter, indicating a heavy organic pollutant load, the chemical oxygen demand (COD) was $71 \mathrm{mg} /$ liter in addition to a remarkable microbiological and biological contamination. The measured toxicity of ambient water has not reached the critical level on microorganism of the bio-based material, so it is suitable for bio-based material to be applied.

The second step was to apply the bio-based material to polluted open streams under variant conditions of discharge, contact time and load of pollution as follows: 1-Extreme flow condition (in the study area "1", the discharge ranged from 100,000 (low flow) to $900,000 \mathrm{~m}^{3} /$ day (shock flow) with an average of $500,000 \mathrm{~m}^{3} /$ day) and low contact time (8 minutes for drain "1", 1.6 hours for drain "2"). 2- The second condition was: Low flow condition (case study " 2 " of a discharge of $20,000 \mathrm{~m}^{3} /$ day) with a shock polluted load and contact time of ( 0.45 hours). The eight selected WQPs for AWQI calculation are: BOD, COD, TSS, $\mathrm{NH}_{3}, \mathrm{FC}, \mathrm{DO}, \mathrm{TP}$ and oil \& grease

\section{APPLICATION \& RESULTS}

\section{Bench-scale results}

For WQPs results, figure 2 shows the measured results for both control (CS) and test samples (TS) for the selected WQPs. The figure illustrates the overall improvement in WQPs values over the period of bench-scale test (14 days) and relative improvement between CS and TS along the same period as summarised in table 2 .

The AWQIs (Table 3 and graph Figure 3), illustrate the improvement in AWQIs of selected WQPs. The best effect of the bio-based material ranged between " $22 \%$ " to " $26 \%$ " during 14 days of application.
Table 2 - Overall/ relative improvement in WQPs bench-scale test

\begin{tabular}{lcc}
\hline Parameter (WQP) & $\begin{array}{c}\text { Max. Relative } \\
\text { improvement } \\
\text { TS/ CS \% }\end{array}$ & $\begin{array}{c}\text { Overall } \\
\text { improvement } \\
\text { TS \% }\end{array}$ \\
\hline BOD & $27 \%$ @ H12 & 71 \\
\hline COD & $16 \%$ @ H8 & 70 \\
\hline $\mathbf{H}_{\mathbf{2}}$ S & $47 \%$ @ H4 & 97 \\
\hline TSS & $66 \%$ @ H24 & 88 \\
\hline $\mathbf{N H}_{3}$ & $27 \%$ @ H8 & 73 \\
\hline E. coli & $30 \%$ @ 24 & 100 \\
\hline FC & $20 \%$ @ H168 & 100 \\
\hline FS & $61 \%$ H12 & 100 \\
\hline Notes: CS: control sample; TS: test sample &
\end{tabular}

Table 3 - AWQI and improvement percentage for bench-scale test

\begin{tabular}{lcccccccc}
\hline \multicolumn{7}{c}{ bench-Scale test } \\
\hline & $\mathrm{H}_{0}$ & $\mathrm{H}_{4}$ & $\mathrm{H}_{8}$ & $\mathrm{H}_{12}$ & $\mathrm{H}_{24}$ & $\mathrm{H}_{48}$ & $\mathrm{H}_{168}$ & $\mathrm{H}_{336}$ \\
\hline $\mathrm{CS}$ & 366 & 356 & 341 & 319 & 290 & 246 & 169 & 112 \\
\hline $\mathrm{TS}$ & 366 & 321 & 270 & 257 & 216 & 193 & 136 & 93 \\
\hline Improving & $0 \%$ & $10 \%$ & $21 \%$ & $20 \%$ & $26 \%$ & $22 \%$ & $19 \%$ & $16 \%$ \\
\hline
\end{tabular}

Notes; Hn: WQI at hour n; TS: test sample; CS: control sample

\section{Field work (surface drainage water)}

Study area "1": High flow condition with intermediate shock flow

The field investigation has been conducted over 27 days. For experimental work, the proposed study area has an agriculture drain "1" discharges directly into main drain "2" at $\mathrm{km} 19.85$ as illustrated in figure 4. The drains were selected for this study as an actual case study, where it receives discharge from predominantly untreated or poorly treated domestic and industrial wastewater, and drainage return flow from agriculture land and fish farming. The dosing solution was prepared by mixing the compound in fresh water. The result of this process is an active aqueous solution, which can be dosed into the water system. The process requires $20 \sim 50 \mathrm{~L}$ of fresh water per kg of product. For the study area, the dosing rate has been designed as shown in table 4 based on the designed average discharge of $500,000 \mathrm{~m}^{3} /$ day. 


\section{Fast-Track in-Stream Action to Enhance the Oxidative Capacity within Watershed}

Table 4: Dosing rate \& schedule

\begin{tabular}{|c|c|c|c|}
\hline Day & $\begin{array}{c}\text { Material } \\
\text { added } \\
\text { (kg/ day) }\end{array}$ & $\begin{array}{c}Q_{\text {Ave }} \\
1000 \\
\mathrm{~m}^{3} / \text { day }\end{array}$ & $\begin{array}{c}\text { Ambient } \\
\text { concentration } \\
\text { mg/L }\end{array}$ \\
\hline 1 & 275 & 110.2 & 2.5 \\
\hline 2 & 225 & 716 & 0.3 \\
\hline 3and 4 & $175 * 2$ & $761.9 * 2$ & 0.2 \\
\hline 5 & 150 & 881.3 & 0.2 \\
\hline 6 and 7 & $125 * 2$ & $798.7 * 2$ & 0.2 \\
\hline 8 and 9 & $100 * 2$ & $587.5 * 2$ & 0.2 \\
\hline $\begin{array}{c}10 \text { and } \\
11\end{array}$ & $80 * 2$ & $422.3 * 2$ & 0.2 \\
\hline 12 to 15 & $75 * 4$ & $477.4 * 4$ & 0.2 \\
\hline $\begin{array}{c}16 \text { and } \\
17\end{array}$ & $50 * 2$ & $807.8 * 2$ & 0.1 \\
\hline
\end{tabular}

A set of two tanks of size $3 \mathrm{~m}^{3}$ each have been installed at the outlet of drain " 1 " as in figure 5, to activate the material. Five tanks of size $\left(0.5 \mathrm{~m}^{3}\right)$ were used for dosing. The dosing station was chosen at the outlet of the rising pump station (Figure 4), where the process was as follows:
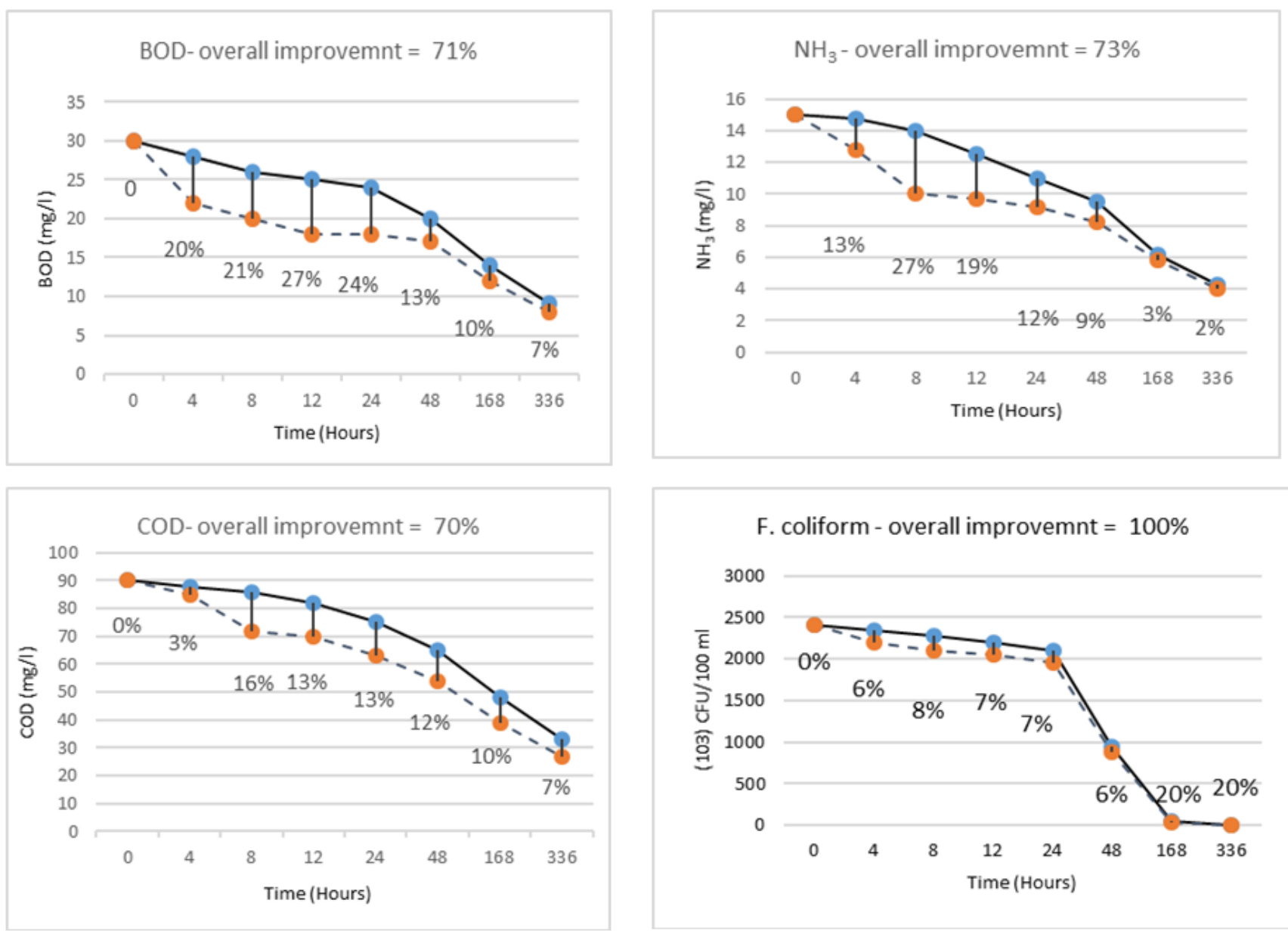

F. coliform - overall improvemnt $=100 \%$

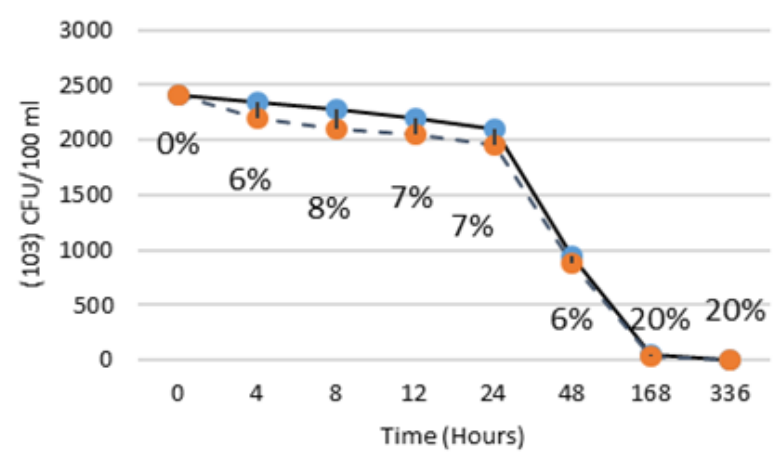



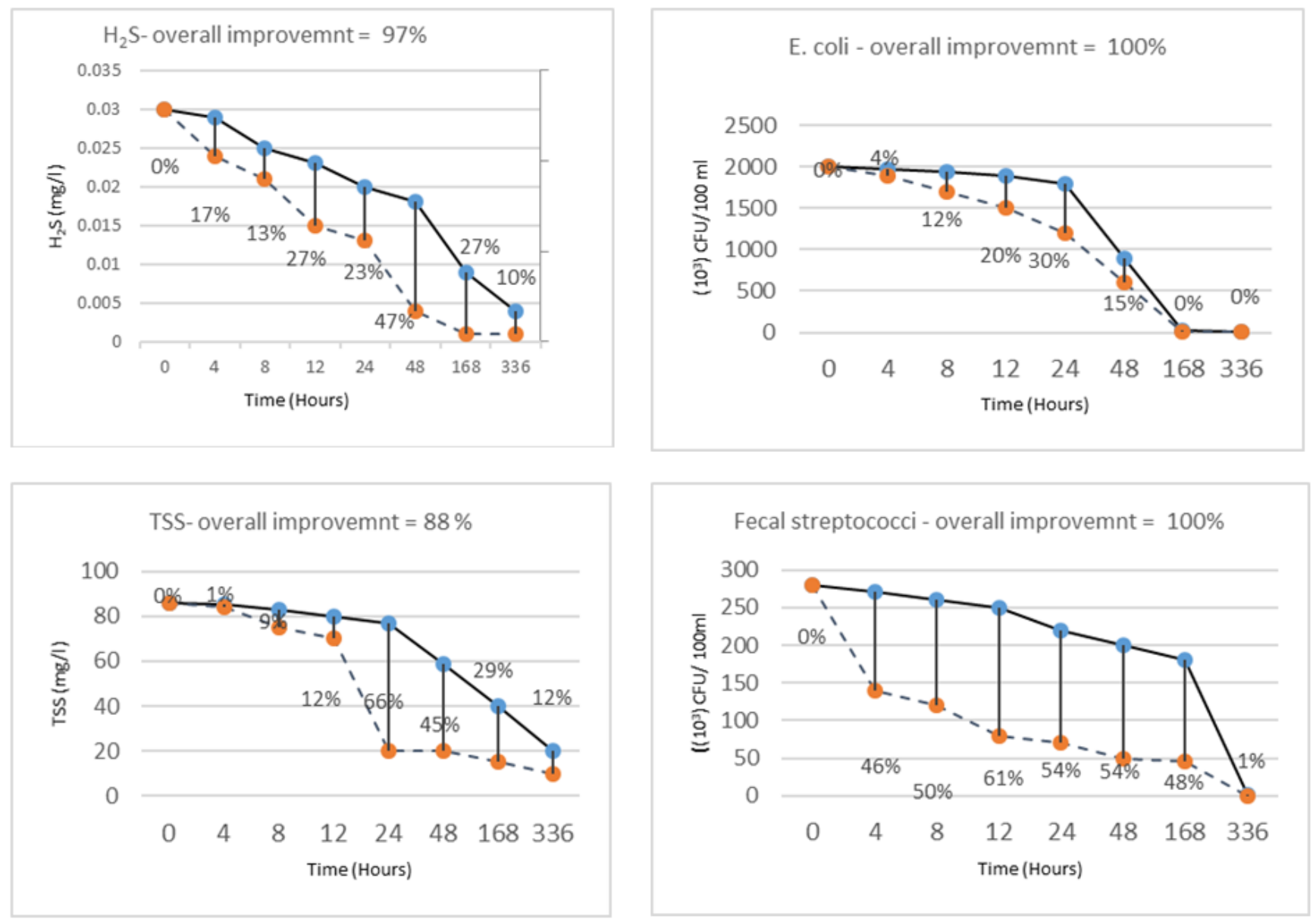

Figure 2: Measured values, percentage and overall improvement of selected WQPs (Bench scale)

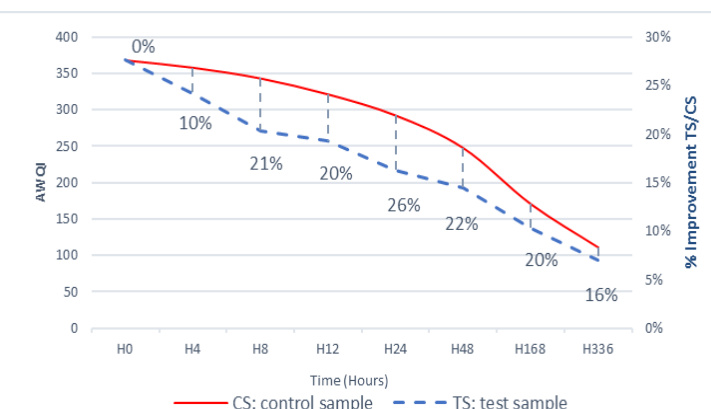

Figure 3: AWQI improvement for bench-scale test

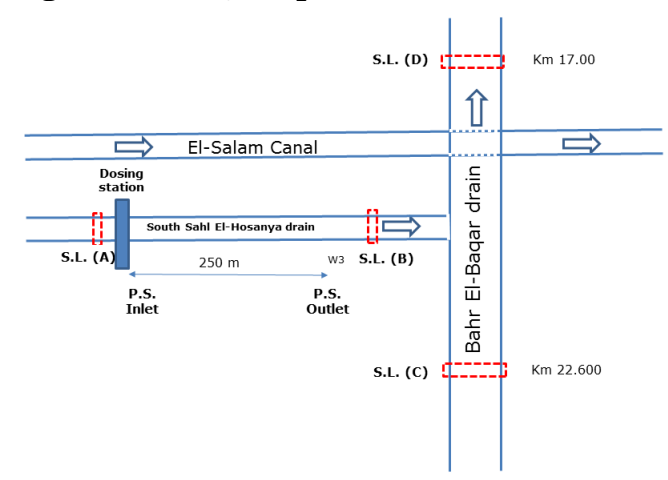

Note: S. L.: sampling location, P.S.: pump station

Figure 4: Samples locations (surface water and sediment) for drain 1, 2 of study area "1"

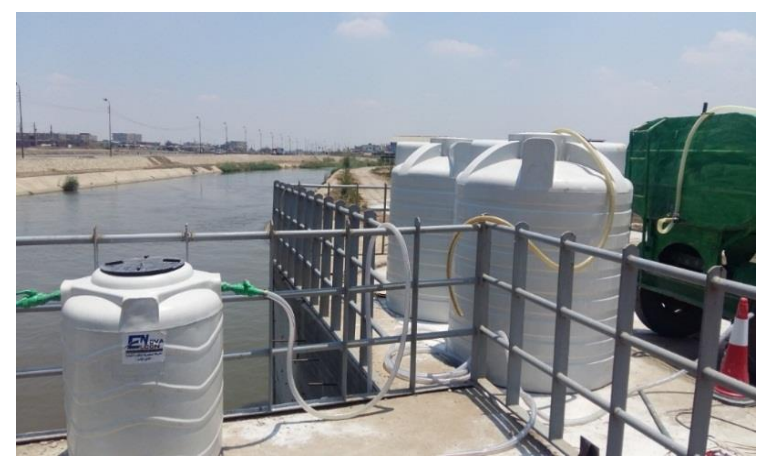

Figure 5: Dosing station

- Place the required mass of compound into the tank and fill with water, - Apply a mix process up to 5 hours, - Place the tank to the designated dosing location and run a hose down into the dosing point with an estimate rate of $10 \mathrm{~L} / \mathrm{min}$.

A set of samples have been collected from four different locations (S.L) as shown in figure 4, over 27 days of investigation, according to following designed time schedule: at $1^{\text {st }}, 6^{\text {th }}, 9^{\text {th }}, 13^{\text {th }}, 15^{\text {th }}$ day of application and $6^{\text {th }}, 10^{\text {th }}$ day after application. A daily monitoring of discharge has been recorded. Samples were assessed for around 44 physio-chemical and biological WQPs for field investigation. However, $\mathrm{pH}$, Temperature (T) and DO were measured in situ using a portable meter. 


\section{Fast-Track in-Stream Action to Enhance the Oxidative Capacity within Watershed}

For the WQPs results: Figure 6 and table 5, shows the measured values for the 4 sampling locations (S. L. (A), (B), (C), (D)) for the selected WQPs. The figure illustrates the overall improvement in WQPs values over the period of field investigation (27 days) and relative improvement between S. L. (B)/ (A) (Stream "1") and S. L. (D)/ (C) (stream "2") along the same period as summarised in table 5 .

Table 5: Relative improvement in WQPs - study area "1"

\begin{tabular}{lcc}
\hline $\begin{array}{l}\text { Parameter } \\
\text { (WQP) }\end{array}$ & $\begin{array}{c}\text { Max. Relative } \\
\text { improvement } \\
\text { S.L. (B)/ S. L. (A) }\end{array}$ & $\begin{array}{c}\text { Max. Relative } \\
\text { improvement S.L. } \\
\text { (C)/ S. L. (D) }\end{array}$ \\
\hline BOD & $24 \%$ @ D15 & $40 \%$ @13 \\
\hline COD & $26 \%$ @ AD6 & $21 \%$ @ D9 \\
\hline DO & $15 \%$ @D7 & $-10 \%$ @ D13 \\
\hline TSS & $47 \%$ @6 & $61 \%$ @ D6 \\
\hline NH & 37\% @ D15 & $43 \%$ @ D13 \\
\hline TP & $34 \%$ @1 & $27 \%$ @ D6 \\
\hline FC & $64 \%$ @ D & $78 \%$ @13 \\
\hline Oil \& grease & $50 \%$ @6 & $57 \%$ @6 \\
\hline
\end{tabular}

For AWQI results: The highest improvement in AWQI ranged from " $21 \%$ " to " $26 \%$ " (Table 6, Figure 7);

- At the time of maximum capacity of raising pump station (maximum irrigation water requirements period), in addition to the slightly effect of bio-based material, the AWQI was greatly affected by dilution (the biological contamination in drainage water is relatively small).

- The slightly effect of the material was noticeable in drain " 2 " of study area " 1 " where changing in odor and water transparency has been recognized at S. L. (D) (3 km downstream drain " 1 ").

Study area "2" Low flow condition with intermediate shock pollution load

The field investigation has been conducted along 38 days on the canal of study area " 2 ". It is an un-official canal that is fed directly from drain " 2 " of study area " 1 " by two main pipes of one-meter diameter each, with an average measured discharge of $20 \mathrm{~m}^{3} /$ day, length is $5 \mathrm{~km}$ and water applications are irrigation and fish farming.

For implementation and dosing: One main tank of size $3 \mathrm{~m}^{3}$ has been used as mixer to activate the material and other one tank of size $0.5 \mathrm{~m}^{3}$ for dosing. The dosing station for the activated product was chosen at a distance of $500 \mathrm{~m}$ away from canal's intake. The dosing rate has been designed as listed in table 7, based on average canal's discharge of about $20,000 \mathrm{~m}^{3} /$ day. Samples have been collected from three different sampling locations (Figure 8) over a period of 38 days as following schedule: 3rd, 7th, 10th, 14th day of application, and $1^{\text {st }}$ and $2^{\text {nd }}$ day of post application.

For WQPs results: figure 9 and table 8, shows the measured values for the 4 sampling locations (S. L. (A), (B), (C)) for the selected WQPs. The figure illustrates the relative improvement in WQPs values over the period of field test (38 days) between S. L. (C)/ (A) and S. L. (B)/ (A) as summarised in table 8.

For AWQI results: A sudden shock polluted flow discharged from a branch which located few meters from S. L. (B). The shock flow came from a fish farming draining water.

-The highest improvement in AWQI ranged from "13\%" to "16\%" happened at S. L. (C) after receiving the shock pollution load during the application of material.

- The effect of the bio-based material was noticeable on study area "2", where changing in odor and transparency of water has been recognized at point S. L. (C) at day D21 up to the end of field work.

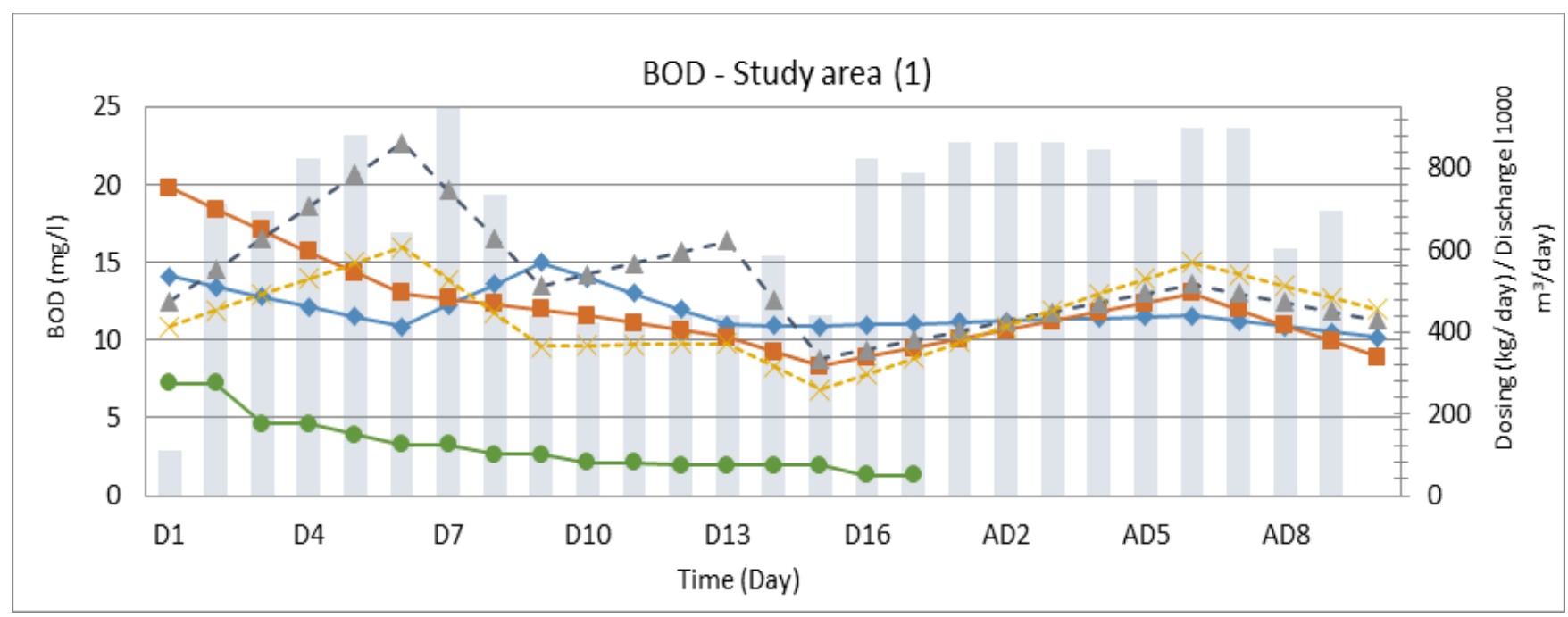



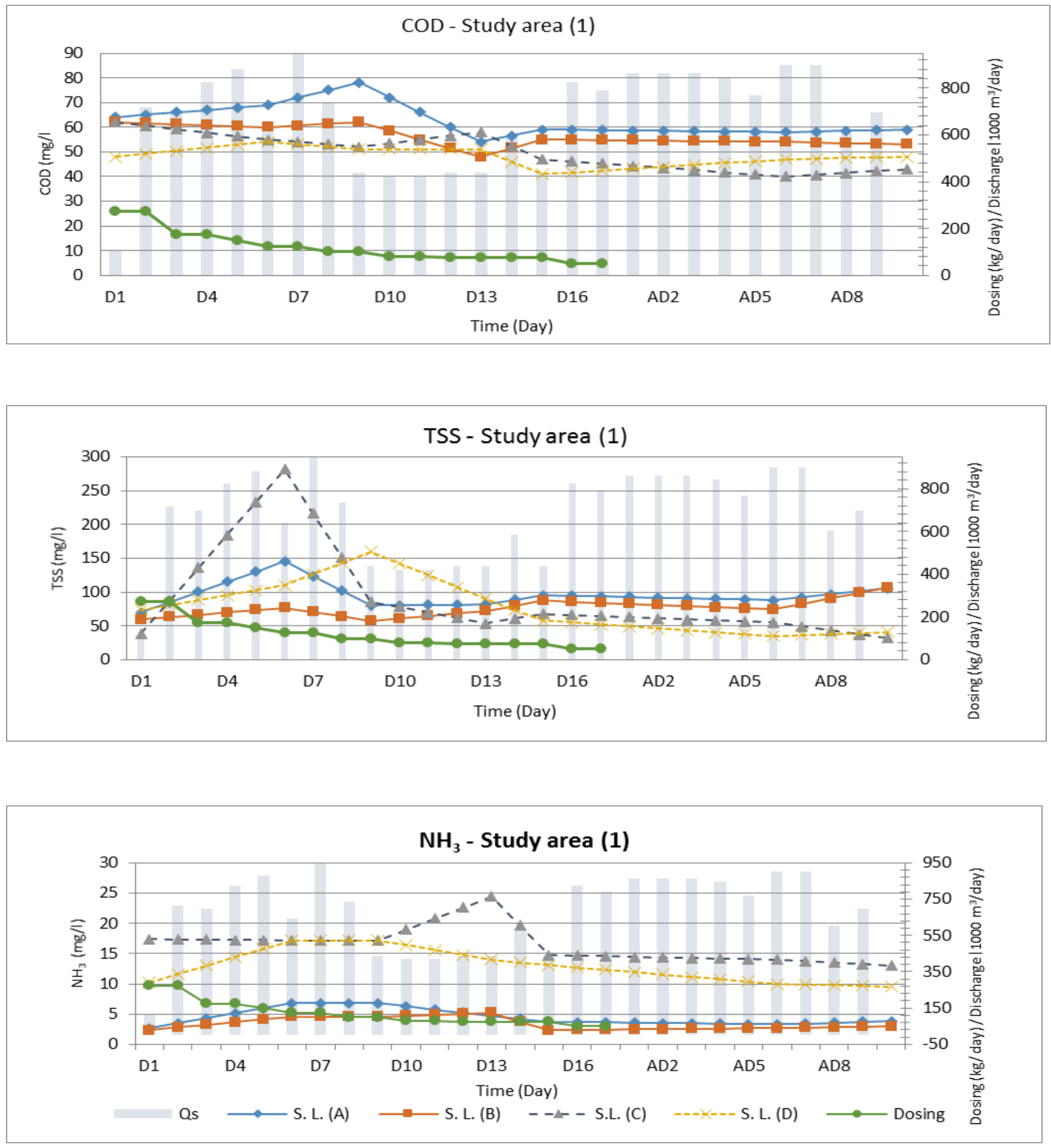


\section{Fast-Track in-Stream Action to Enhance the Oxidative Capacity within Watershed}
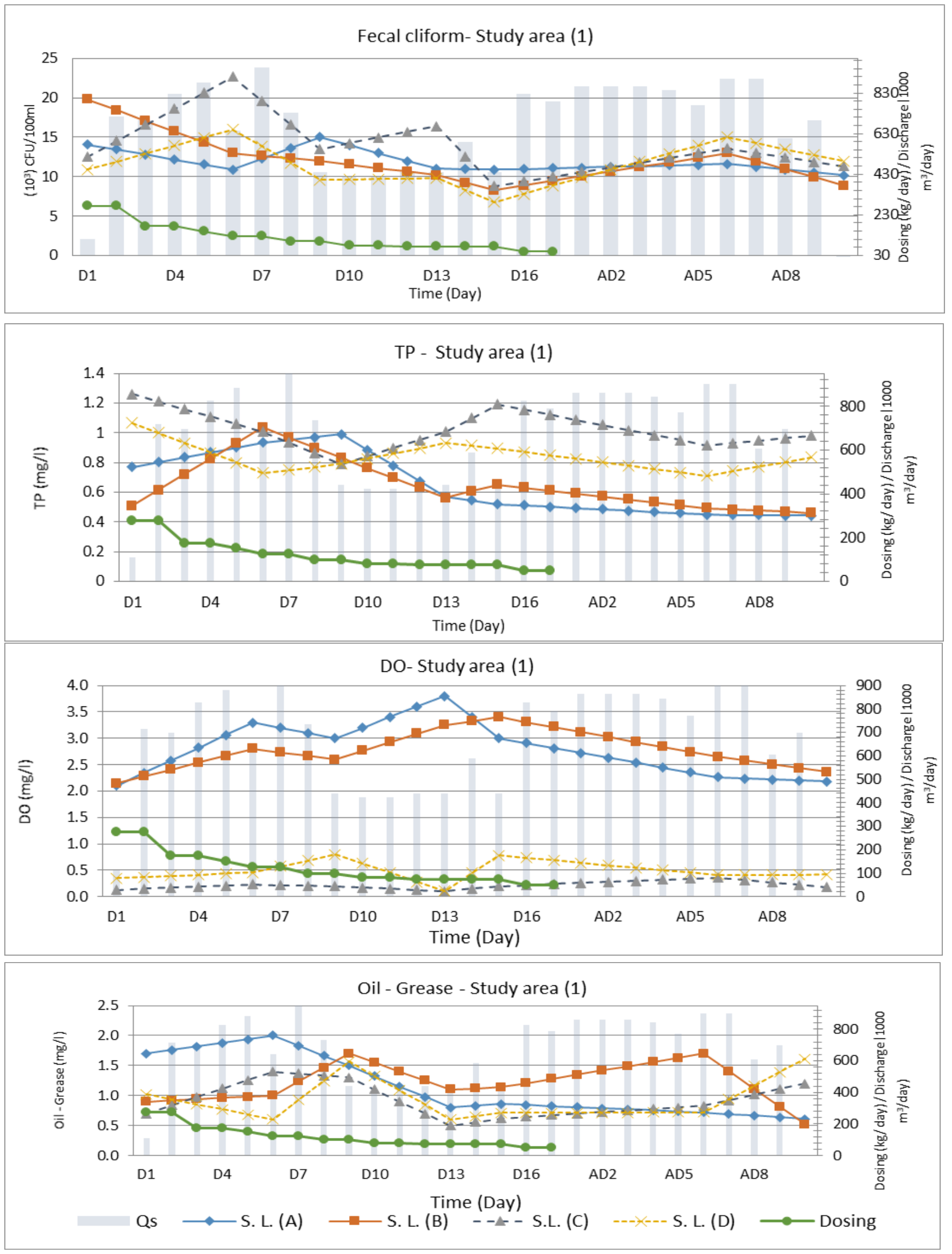

Figure 6: Measured values, percentage and overall improvement of selected WQPs (study area "1")

Retrieval Number: C4764029320/2020@BEIESP DOI: 10.35940/ijeat.C4764.029320 Journal Website: www.ijeat.org

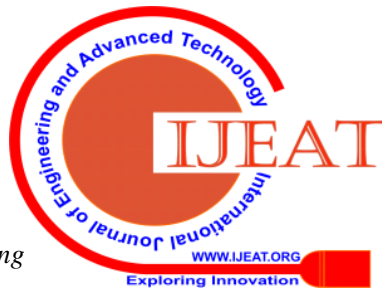


Table 6: Results of AWQI for study area "1"

\begin{tabular}{|c|c|c|c|c|c|c|c|c|c|c|c|c|c|}
\hline \multirow[t]{2}{*}{ Item } & \multicolumn{13}{|c|}{ AWQI } \\
\hline & D1 & D2 & D3 & D4 & D5 & D6 & D7 & D8 & D9 & D10 & D11 & D12 & D13 \\
\hline S. L.(A) & 367 & 356 & 346 & 335 & 325 & 314 & 350 & 386 & 422 & 415 & 408 & 402 & 395 \\
\hline S. L. (B) & 272 & 267 & 262 & 258 & 253 & 248 & 283 & 317 & 352 & 361 & 371 & 380 & 389 \\
\hline S. L. (C) & 405 & 383 & 361 & 339 & 317 & 295 & 313 & 331 & 350 & 421 & 492 & 564 & 635 \\
\hline S. L. (D) & 300 & 293 & 286 & 279 & 273 & 266 & 286 & 306 & 326 & 364 & 402 & 440 & 477 \\
\hline \multirow[t]{2}{*}{$\mathbf{Q}$} & & & & & & & & & & & & & \\
\hline & 110 & 716 & 698 & 826 & 881 & 643 & 955 & 734 & 441 & 422 & 422 & 441 & 441 \\
\hline Dosing & 275 & 275 & 175 & 175 & 150 & 125 & 125 & 100 & 100 & 80 & 80 & 75 & 75 \\
\hline $\begin{array}{c}\text { Reduction \% } \\
\text { (S. L. (A) - S. L. (B)) }\end{array}$ & $26 \%$ & $25 \%$ & $24 \%$ & $23 \%$ & $22 \%$ & $21 \%$ & $19 \%$ & $18 \%$ & $17 \%$ & $13 \%$ & $9 \%$ & $5 \%$ & $1 \%$ \\
\hline $\begin{array}{c}\text { Reduction \% } \\
\text { (S. L. (C) - S. L. (D)) }\end{array}$ & $26 \%$ & $24 \%$ & $21 \%$ & $18 \%$ & $14 \%$ & $10 \%$ & $9 \%$ & $8 \%$ & $7 \%$ & $13 \%$ & $18 \%$ & $22 \%$ & $25 \%$ \\
\hline
\end{tabular}

\begin{tabular}{cccccccccccccc}
\hline & & & & \multicolumn{1}{c}{ AWQI } \\
\hline D14 & D15 & D16 & D17 & AD1 & AD2 & AD3 & AD4 & AD5 & AD6 & AD7 & AD8 & AD9 & AD10 \\
\hline 399 & 403 & 391 & 380 & 368 & 356 & 344 & 332 & 321 & 309 & 290 & 271 & 252 & 233 \\
\hline 375 & 360 & 353 & 346 & 340 & 333 & 326 & 319 & 313 & 306 & 284 & 262 & 240 & 218 \\
\hline 550 & 464 & 449 & 434 & 419 & 404 & 389 & 373 & 358 & 343 & 323 & 302 & 282 & 262 \\
\hline 449 & 422 & 409 & 396 & 383 & 371 & 358 & 345 & 332 & 319 & 302 & 285 & 268 & 251 \\
\hline 588 & 441 & 826 & 789 & 863 & 863 & 863 & 845 & 771 & 900 & 900 & 606 & 698 \\
\hline 75 & 75 & 50 & 50 & & & & & & & & & \\
\hline $6 \%$ & $11 \%$ & $10 \%$ & $9 \%$ & $8 \%$ & $6 \%$ & $5 \%$ & $4 \%$ & $2 \%$ & $1 \%$ & $2 \%$ & $3 \%$ & $5 \%$ & $7 \%$ \\
\hline $18 \%$ & $9 \%$ & $9 \%$ & $9 \%$ & $8 \%$ & $8 \%$ & $8 \%$ & $8 \%$ & $7 \%$ & $7 \%$ & $6 \%$ & $6 \%$ & $5 \%$ & $4 \%$ \\
\hline
\end{tabular}

Notes: S. L. (n): Sampling location number n, Q: recorded daily discharge, Shaded cells where bio-based material was applied, where, Dn: day of application, AP: post-application day.

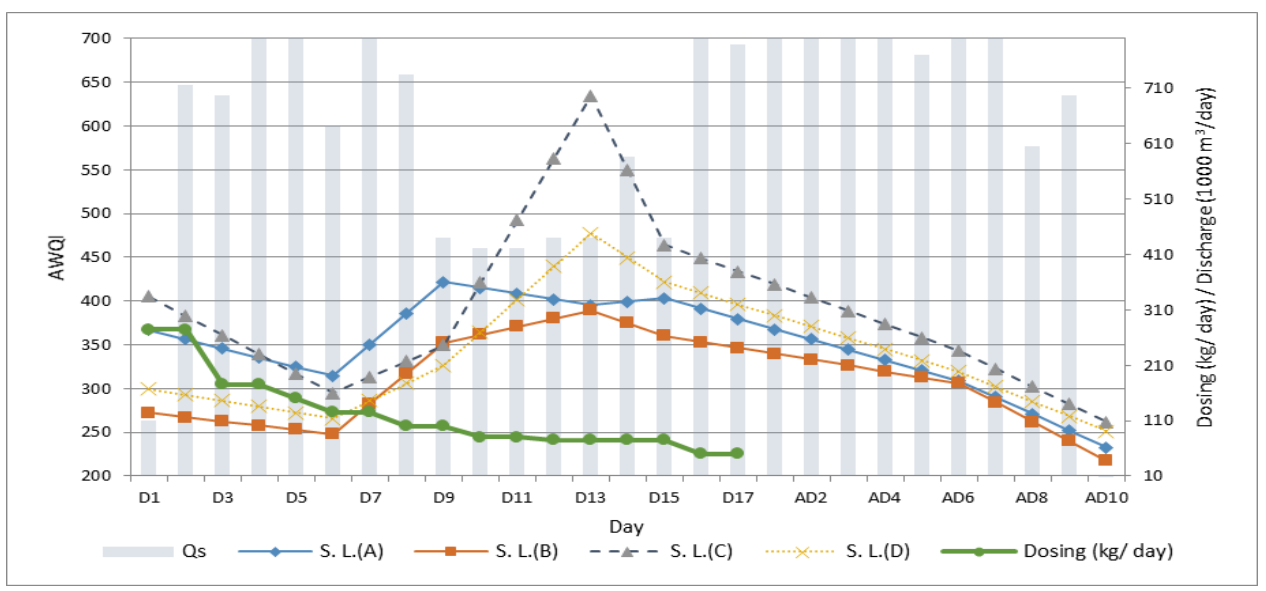

Figure 7: AWQI results for field test (High flow condition, study area "1")

\section{Semi-structural interview}

An interview with the farmers in the study area has been done. The purpose of such interviews was to investigate the impact of applying the bio-base material in water and detect the effect to the fish and plants and rather more to the odor. It was reported that a remarkable improvement in water transparency and odor have been improved.
Table 7: Dosing schedule

\begin{tabular}{ccc}
\hline Day & $\begin{array}{c}\text { Material added } \\
(\mathbf{k g} / \text { day) }\end{array}$ & $\begin{array}{c}\text { Ambient } \\
\text { concentration } \mathbf{~ m g} / \mathbf{L}\end{array}$ \\
\hline $\mathbf{1}$ and 2 & $69 * 2$ & 3 \\
\hline $\mathbf{3}$ and 4 & $57.5 * 2$ & 2.5 \\
\hline $\mathbf{5}$ and 6 & $46 * 2$ & 2 \\
\hline $\mathbf{7}$ and $\mathbf{8}$ & $34.5 * 2$ & 1.5 \\
\hline $\mathbf{9}$ and 10 & $23 * 2$ & 1 \\
\hline $\mathbf{1 1}$ till 15 & $17.25 * 5$ & 0.75 \\
\hline $\mathbf{Q}$ & &
\end{tabular}

$$
Q_{\text {Ave }}=20,000 \text { m }^{3} / \text { day }
$$


Fast-Track in-Stream Action to Enhance the Oxidative Capacity within Watershed

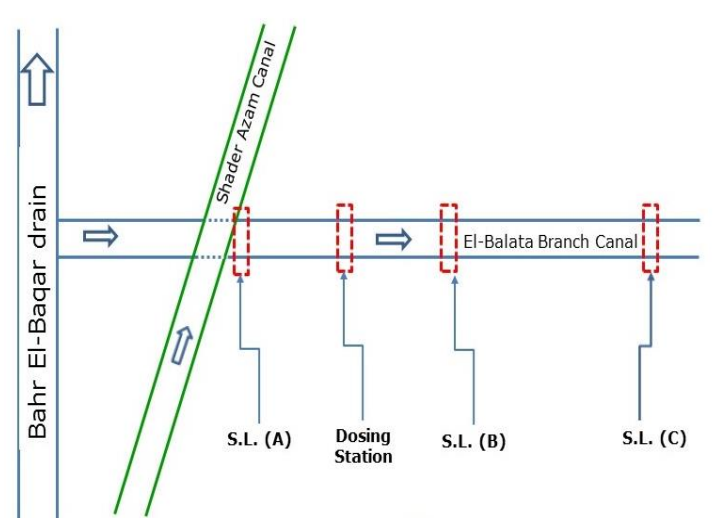

Table 8: Relative improvement in WQPs - study area

Figure 8: Grab samples locations (surface water and sediment) for Study area "2"

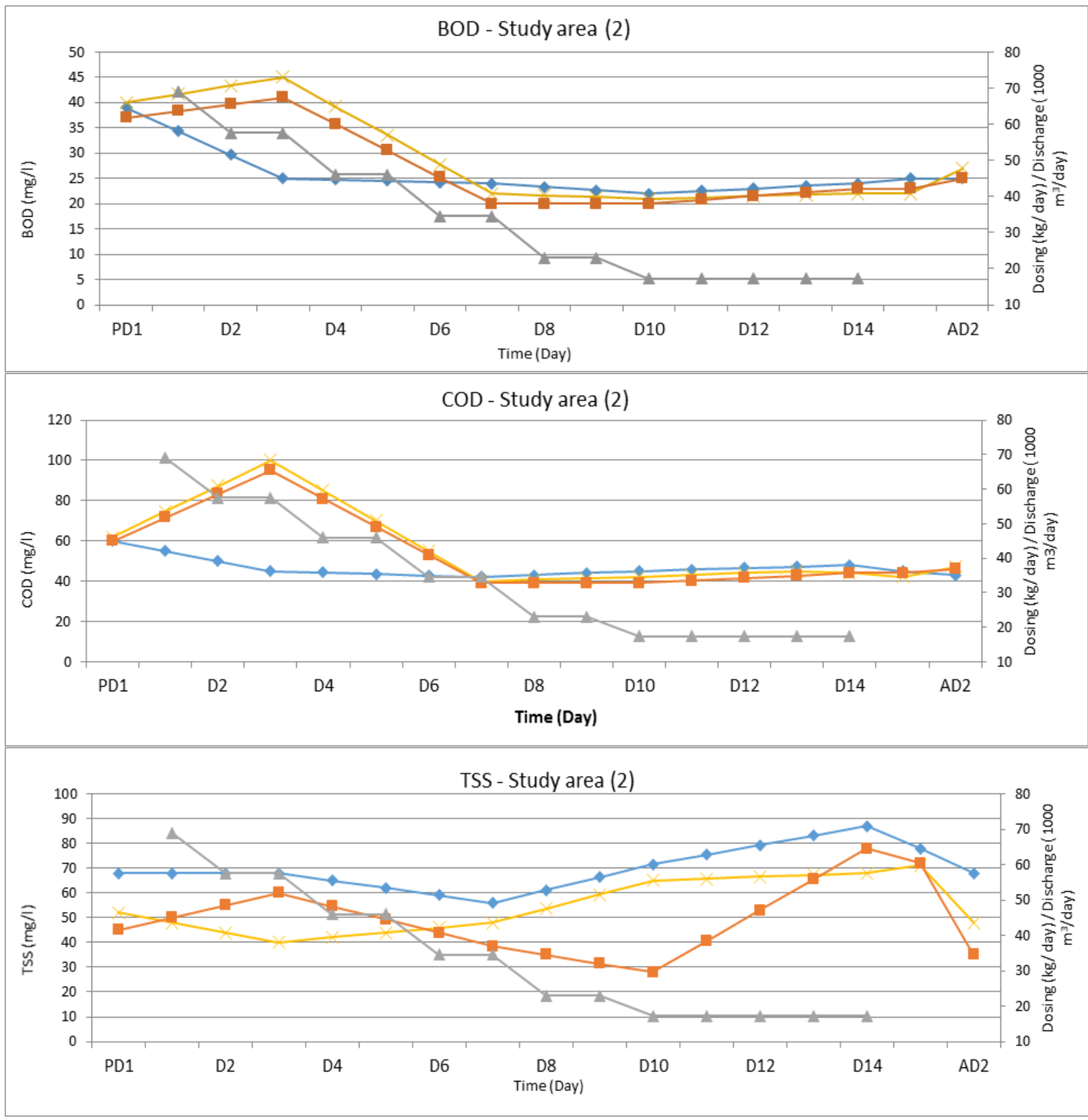

Retrieval Number: C4764029320/2020@BEIESP

DOI: 10.35940/ijeat.C4764.029320

Journal Website: www.ijeat.org
Published By:

Blue Eyes Intelligence Engineering \& Sciences Publication

\begin{tabular}{lcc}
\hline $\begin{array}{l}\text { Parameter } \\
\text { (WQP) }\end{array}$ & $\begin{array}{c}\text { Max. Relative } \\
\text { improvement S.L. (C)/ S. } \\
\text { L. (A) }\end{array}$ & $\begin{array}{c}\text { Max. Relative } \\
\text { improvement S.L. (B)/ S. } \\
\text { L. (A) }\end{array}$ \\
\hline BOD & $17 \%$ @7 & $8 \%$ @ D7 \\
\hline COD & $13 \%$ @ D10 & $8 \%$ @ D14 \\
\hline DO & $19 \%$ @ D10 & $7 \%$ D3 \\
\hline TSS & $61 \%$ @10 & $35 \%$ @4 \\
\hline NH 3 & $8 \%$ @ D7, D8 & $6 \%$ D10 \\
\hline TP & $7 \%$ @10 & $9 \%$ D14 \\
\hline FC & $25 \%$ @ D10 & $18 \%$ @3 \\
\hline $\begin{array}{l}\text { Oil \& } \\
\text { grease }\end{array}$ & $39 \%$ D10 & $13 \%$ D3 \\
\hline
\end{tabular}

\section{"2"}




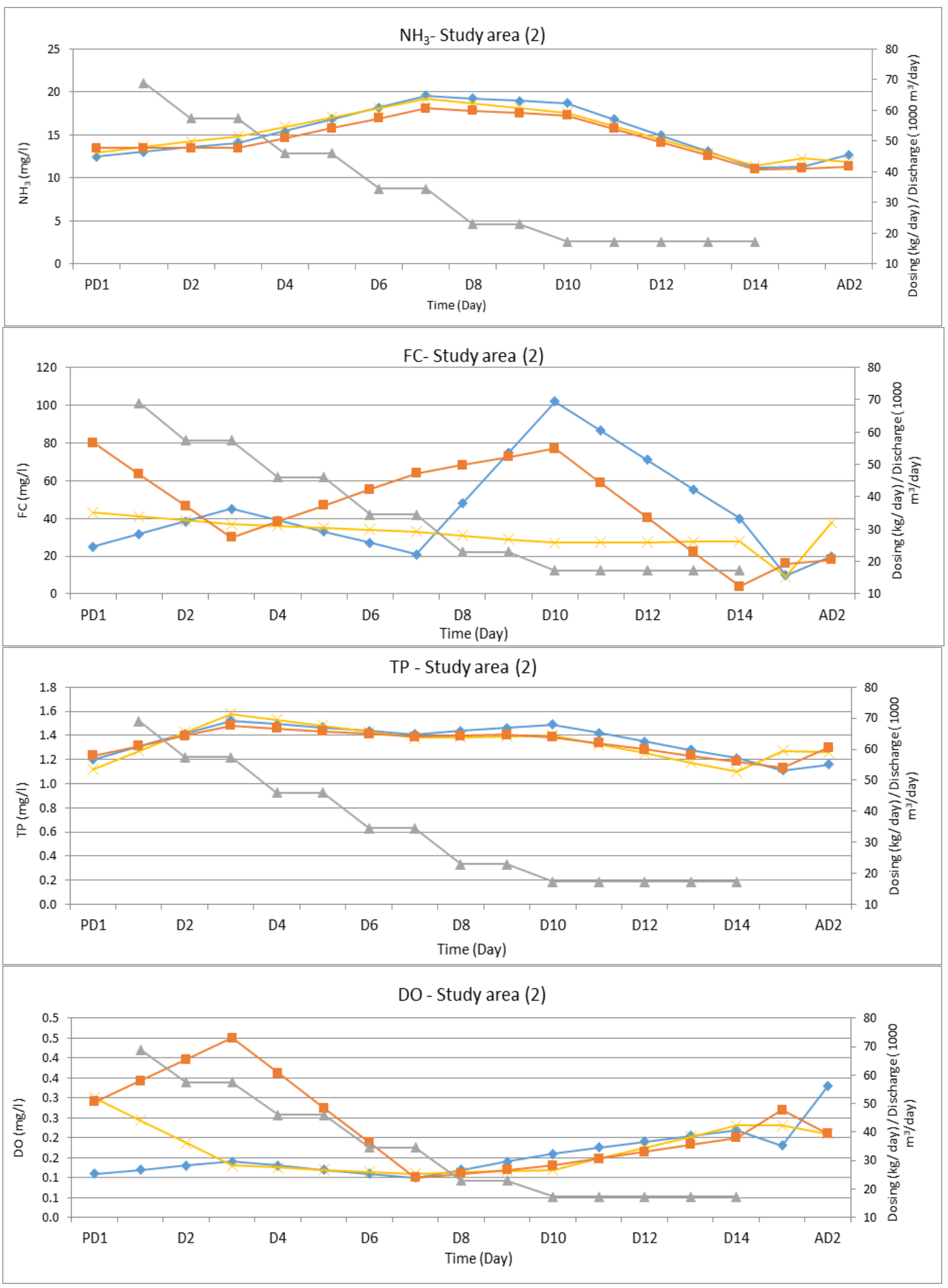

Retrieval Number: C4764029320/2020@BEIESP DOI: 10.35940/ijeat.C4764.029320 Journal Website: www.ijeat.org
Published By:

Blue Eyes Intelligence Engineering 1024 \& Sciences Publication

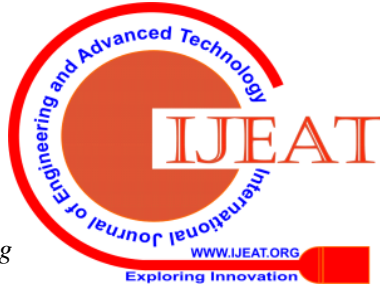




\section{Fast-Track in-Stream Action to Enhance the Oxidative Capacity within Watershed}

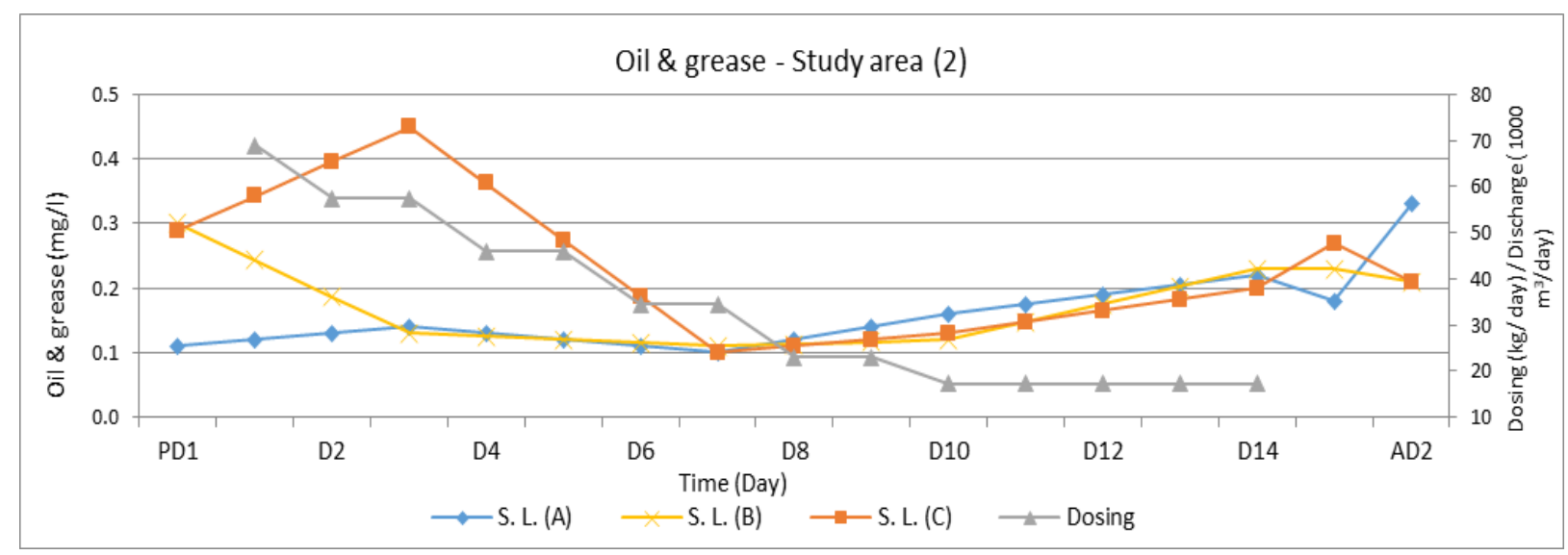

Figure 9: Measured values, percentage and overall improvement of selected WQPs (study area 2)

Table 9: Results of AWQI for Study area "2"

\begin{tabular}{lccccccc}
\hline & \multicolumn{7}{c}{ AWQI } \\
\hline & PD1 & D1 & D2 & D3 & D4 & D5 & D6 \\
\hline S. L. (A) & 376 & 383 & 373 & 363 & 365 & 367 & 369 \\
\hline S. L. (B) & 388 & 428 & 449 & 471 & 445 & 418 & 392 \\
\hline S. L. (C) & 381 & 401 & 417 & 433 & 411 & 390 & 368 \\
\hline Dosing & & 69 & 58 & 58 & 46 & 46 & 35 \\
\hline SP1/ SP3 improvement & $-1 \%$ & $-5 \%$ & $-12 \%$ & $-19 \%$ & $-13 \%$ & $-6 \%$ & $0 \%$ \\
\hline
\end{tabular}

\begin{tabular}{cccccccccc}
\hline \multicolumn{1}{c}{ AWQI } \\
\hline D7 & D8 & D9 & D10 & D11 & D12 & D13 & D14 & AD1 & AD2 \\
\hline 372 & 380 & 389 & 397 & 382 & 367 & 352 & 337 & 315 & 322 \\
\hline 365 & 360 & 355 & 350 & 341 & 331 & 322 & 313 & 313 & 318 \\
\hline 347 & 343 & 338 & 334 & 329 & 324 & 318 & 313 & 299 & 295 \\
\hline 35 & 23 & 23 & 17 & 17 & 17 & 17 & 17 & & \\
\hline $7 \%$ & $10 \%$ & $13 \%$ & $16 \%$ & $14 \%$ & $12 \%$ & $10 \%$ & $7 \%$ & $5 \%$ & $8 \%$ \\
\hline
\end{tabular}

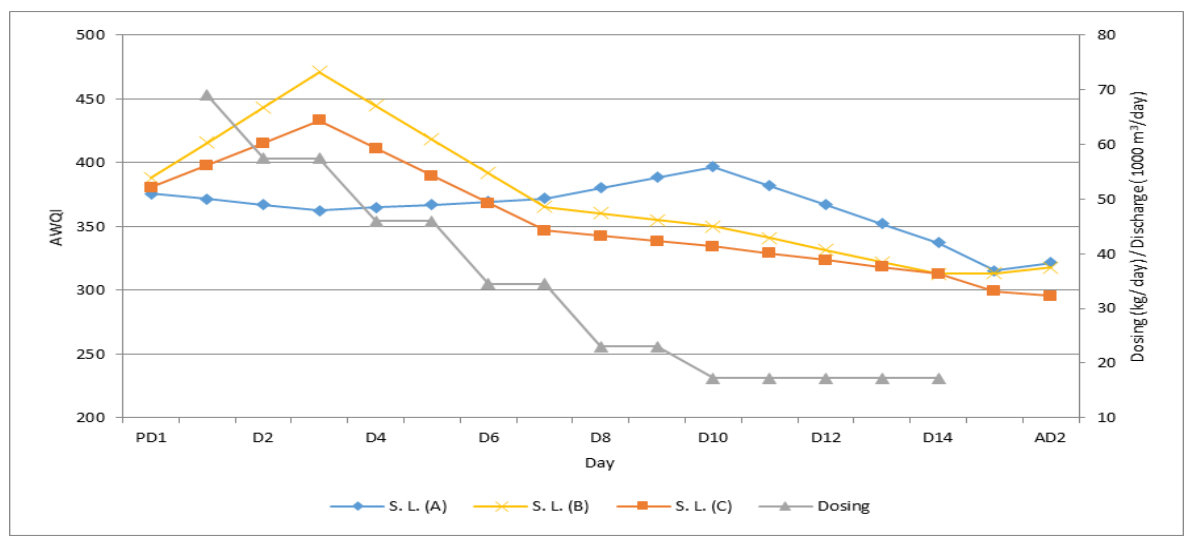

Figure 10: AWQI results for field test (Low flow condition, Study area "2"

\section{CONCLUSIONS}

\section{Bench scale test}

- The results values for individual selected parameters show high improvement in water quality (overall and relative improvement) as shown in (Figure 2, Table 2), where most maximum relative improvement values happened during the first 48 hours;

- The graph in figure3 shows high improvement in AWQI during the period of application of $\mathrm{H} 24$ to H168, varied from $22 \%$ to $26 \%$ respectively (difference in AWQI between CS \& TS);
- Bench scale test proved the capability of bio-based material to clean polluted drainage water under laboratory conditions.

Study area "1": High flow condition with intermediate shock flow

- The results values for individual selected parameters show high improvement in individual water quality as shown in (Figure 6, Table 5), where most maximum results of parameters values happened around D6 and D13 to D16 during the period of chock flow; 
- The graph in figure 7 shows high improvement in relative water quality during the period of application varied from 1 to $26 \%$ in AWQI. This is resulting from both the application of compound and the dilution resulting from sudden shock flow;

- While it shows increase in the value of AWQI during the time of average discharge;

- The application of bio-based material can be limited by a maximum discharge of 500 thousand $\mathrm{m}^{3} /$ day to be cleaned by material in the open stream water systems and suitable retention time;

- The low retention time between inlet (Before treatment) and outlet (after treatment) measuring points limited the ability of the sampling program to capture the full benefit of the bio-based material, even so, the limited retention time was enough to allow slight enhancement in AWQI;

- The sudden shock flow that was pumped during application time (up to 900 thousand $\mathrm{m}^{3} / \mathrm{day}$ ), also disturbs the process of cleaning;

- The high discharge of drain 2 was both affected by the application of bio-based material in drain and dilution from the sudden shock flow in which, there was slightly effect on the water quality in drain 2 .

- As overall conclusion for the application of bio-based material in study area "1": the effect of material was observed, but the dose rate should have been adjusted to match the change in discharge.

\section{Study area "2": Low flow condition with intermediate shock pollution load}

- The results values for individual selected parameters show high improvement in individual water quality as shown in (Figure 9, Table 8), where most maximum results of parameters values happened around D3 during the period of chock load and proved by AWQI;

- Figure 10 shows significant improvement in water quality during the period of application varied from " $13 \%$ " to " $16 \%$ " as relative AWQI;

- The effect of applying material can easily be noticed in low flow discharge;

- It was clearly observed the improvement in odor and water transparency;

\section{Further works}

- Directing a further study to evaluate the efficiency when applying the bio-based material directly at PSPs (inefficient WWTPs, septic tanks, fish farming, etc.), which end-up with their effluent to water streams;

\section{ACKNOWLEDGMENTS}

- Central Laboratory for Environmental Quality Monitoring (CLEQM) of Ministry of Water Resources and Irrigation;

- Reference laboratory of Holding Company (RLHC);

- Central Laboratory of Ministry of Health (CLMH);

- Egyptian Company for Systems \& Trade (Elcon Nova);

- BiOWiSH Technologies International Inc;

- Water Quality Management Unit of the Ministry of
Water Resources \& Irrigation.

\section{REFERENCES}

1. Talaat El-Gamal, 2018 "Examining an Egyptian Irrigation Network using MASSCOTE Approach", Research gate. https://www.researchgate.net/publication/323827028

2. ElKhazragy M., Matta M. \& Zaher K. (2019), " Watershed Management, a Tool for Sustainable Safe Reuse Practice, Case Study: El-Salam Canal ". Civil and Environmental Research.

3. M. Shaban, B.Urban, A.ElSaadi, M.Faisal "Detection and mapping of water pollution variation in the Nile Delta using multivariate clustering and GIS techniques" Journal of Environmental Management, 2010, 1785-1793.

4. Hulya, 2009 "Utilization of the water quality index method as a classification tool", Environmental Monitoring and Assessment, 167, pp 115-124. http://dx.doi.org/10.1007/s10661-009-1035-1

5. Brown, R. M., McLelland, N.I., Deininger, R. A. and O'Connor, M.F., (1972), A water quality index - crashing the psychological barrier, Indicators of Environmental Quality.

6. El-Sayed A., Shaban M., 2019 " Developing Egyptian water quality index for drainage water reuse in agriculture" Water Environment Federation.

\section{AUTHORS PROFILE}

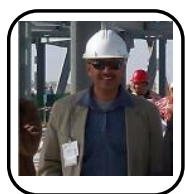

Mohamed L. ElKhazragy, is currently working as a head of Water Quality Management Unit in Water Research Center, Egypt. His experience includes water quality management, domestic wastewater treatment and environmental engineering.

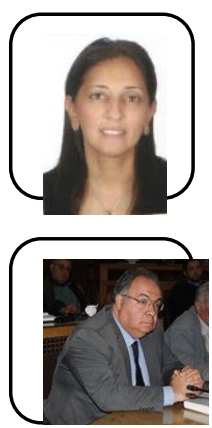

Minerva E. Matta, Associate Professor, Environmental and Sanitary Eng. Division, Faculty of Engineering, Cairo University, Cairo, Egypt.

Khaled Z. Abdallah, Associate Professor, Environmental and Sanitary Eng. Division, Faculty of Engineering, Cairo University, Cairo, Egypt. 